\title{
Expression of P-cadherin (cadherin-3) and E-selectin in the villous trophoblast of first trimester human placenta
}

\author{
Hüseyin Şahin ${ }^{1}$, Yaşam Kemal Akpak², Ufuk Berber ${ }^{3}$, Ismet Gün ${ }^{4}$, Dilaver Demirel ${ }^{3}$, Ali Rüştü Ergür ${ }^{4}$ \\ ${ }^{\prime}$ Department of Obstetrics and Gynaecology, Kasımpaşa Military Hospital, Istanbul, Turkey \\ 2Department of Obstetrics and Gynaecology, Ankara Military Hospital, Ankara, Turkey \\ ${ }^{3}$ Department of Pathology, Haydarpaşa Education Hospital, Gülhane Military Medical Academy, Istanbul, Turkey \\ ${ }^{4}$ Department of Obstetrics and Gynaecology, Haydarpassa Education Hospital, Gülhane Military Medical Academy, \\ Istanbul, Turkey
}

\section{Abstract}

Objective: Although trophoblastic invasion has a critical role in human placental development, very little is known about them. The aim of the present study was to localise the expression of P-cadherin (cadherin-3) and E-selectin in first trimester placenta.

Material and Methods: This study was conducted on 140 patients who had applied to Gülhane Military Medical Academy, Haydarpaşa Education Hospital, Department of Obstetrics and Gynaecology between 2005 and 2006. The patients were divided into three groups: ectopic pregnancy group (Group 1), spontaneous abortion group (group 2) and curettage group (group 3 and/or control group). Patients with a history of systemic diseases (such as thrombophilia), a disease or anatomical diagnosis that may cause recurrent abortion or an aetiological factor for ectopic pregnancy were excluded from the study. Paraffin blocks were stained with E-selectin and P-cadherin in accordance with the procedure. Demographic characteristics of patients (patient age, gravida, parity, number of previous abortions, and last menstrual period) and staining intensities were compared using Analysis of Variance (ANOVA) among groups.

Results: According to the average scale score of P-cadherin staining of cells, the three groups were statistically different from each other $(p=0.0001)$. This difference stems from statistically significantly lower scores in the spontaneous abortion group than in both the ectopic pregnancy group $(\mathrm{p}<0.001)$ and the control group $(\mathrm{p}<0.001)$. E-selectin immunostaining showed no positive staining in the groups.

Conclusion: In placental trophoblasts, decreased P-cadherin immunoreactivity plays a role in the aetiopathogenesis of spontaneous abortion.

(J Turk Ger Gynecol Assoc 2014; 15: 13-7)

Key words: Adhesion molecules, E-selectin, human trophoblast, P-cadherin, placenta

Received: 07 November, $2013 \quad$ Accepted: 21 December, 2013

\section{Introduction}

For the initiation and continuation of a healthy pregnancy, implantation of blastocysts to the endometrium prepared with oestrogen and progesterone stimulations is required. The implantation is, in fact, a union that occurs between the two tissues which are genetically different from each other $(1,2)$. Following endometrial attachment and implantation of the blastocyst, interstitial and intravascular invasion of the maternal tissue by trophoblast occurs and a human haemochorial placenta with foetal origin composed of cytotrophoblast stem cells is formed (3). Inflammatory cells, extracellular matrix components and cell adhesion molecules (CAMs) play a major role in the entire complex chain of events where several reactions take place $(1,2,4-8)$. A potential glitch in one of the stages, such as implantation, invasion and placentation may result in many adverse pregnancy outcomes includ- ing early pregnancy loss (EPL), foetal malformation, foetal growth retardation, and stillbirth (1, 2, 9-14).

Cell adhesion molecules are named according to their functions and structures. The role of cell adhesion molecules in the regulation of many events such as histological and embryological development, cell growth, cell differentiation, cancer and inflammation has been reported in previous studies (1-4, 9-12, 15-19). Selectin among CAMs is particularly involved in the implantation stage (10), whereas the majority of others play a role at every stage, ranging from implantation to placentation (3, 9-12, 15-18). The cadherin family constitutes the largest group of CAMS. To date, studies have defined almost one hundred cadherin molecules. Cadherin, a calciumdependent transmembrane glycoprotein, is required for the expression of specific adhesion molecules in the embryo, cell migration, and coalescence of cells in early embryonic tissues $(3,9,16-18)$. In particular, E-cadherin plays a key role in regulating trophoblastic invasion (19). 
In human reproduction, EPL is one of the most common complications and has an incidence ranging between 50 and 70\% of all conceptions (14). Chromosomal abnormalities are important in the aetiopathogenesis. In recent years, studies at the molecular level have demonstrated the role of the inadequate secretion of CAMs in early pregnancy loss (13). During in vitro studies, the down-regulation of VE-cadherin and up-regulation of E-cadherin have been reported to cause EPL (14). In particular, the insufficient invasion and abnormal placentation by trophoblasts are known to play a role in EPL. However, the presence and role of CAMs and cadherins, in particular in human placenta, are not fully known. The presence of a very low rate of P-cadherin molecule (cadherin-3) has been shown in only the human placenta in previous reports (20).

The purpose of this study is to investigate whether E-selectin and P-cadherin (cadherin-3), among those cell adhesion molecules that have wide-ranging roles in implantation and placentation, have a role in early pregnancy complications by measuring their levels in human villous trophoblast cells of patients with an early pregnancy complication and healthy individuals.

\section{Material and Methods}

\section{Study Design}

The study was approved by the local ethics committee, and written informed consent was obtained from all participants. This retrospective immunohistochemical study was conducted on patients who applied to Gülhane Military Medical Academy, Haydarpaşa Training Hospital, Obstetrics and Gynaecology Department between February 2005 and June 2006, who were operated upon with a diagnosis of ectopic pregnancy and pathologically diagnosed with ectopic pregnancy, had spontaneous abortion with remaining abortion material, and had an elective pregnancy termination for family planning within legal limits or had their pregnancy terminated because of exposure to teratogenic agents. Accordingly, patients were divided into three groups: ectopic pregnancy group (group 1), spontaneous abortion group (group 2) and curettage group (group 3 or control group). Demographic characteristics of patients (patient age, gravida, parity, number of previous abortion and last menstrual period) were retrieved from the patients' follow-up cards and hospitalisation files held in the department. Patients with a history of systemic disease, thrombophilia, congenital uterine anomaly, sub-mucous and/or intramural myoma greater than $4 \mathrm{~cm}$ and with an aetiological factor for recurrent abortion or ectopic pregnancy in their past medical history were excluded from the study. In addition, those patients whose materials were subjected to coagulation necrosis and those showing no chorionic villus under light microscopy were excluded from the study. Materials of the three different groups in the study were evaluated by only one pathologist without specifying the group of the patients in order to minimise inter- and intra-observer variability. For immunohistochemical staining, we selected E-selectin and P-cadherin, which are particularly applicable to paraffin blocks and are known to be effective in both the implantation and placentation.

\section{Procedures and Methods}

We have used the paraffin blocks selected in accordance with predetermined cases from the archive between February 2005 and June 2006. Sections from each block were stained with haematoxylin-eosin and examined. Two sections with a thickness of $3 \mu \mathrm{m}$, including one for negative control and one for testing purposes, were taken on positively charged slides from selected blocks for E-selectin and P-cadherin applications. The sections were incubated for 18 hours at $56^{\circ} \mathrm{C}$ and rehydrated with distilled water following the standard deparaffinisation with two different xylene solutions and three different ethanol solutions. After the prepared sections underwent the antigen retrieval procedure with $10 \%$ Citrate for $35 \mathrm{~min}$ at $100^{\circ} \mathrm{C}$, endogenous peroxidase was deactivated with $3 \%$ hydrogen peroxide. In accordance with the recommended procedures, after incubation with P-cadherin and E-selectin primary antibodies for 30 min and 18 hours, respectively, 3,3'Diaminobenzidine (DAB) chromogen and Mayer's haematoxylin stains were performed before immunohistochemical procedures were completed. In this study, the primary antibodies P-cadherin Ab-1 clone $56 \mathrm{C} 1$ (Thermo Fisher Scientific Anatomical Pathology, California, USA) and E-selectin P2H3 (Santa Cruz Biotechnology, Texas, USA) were used. Preparations were evaluated by light microscopy. The cells were defined as positively or negatively stained on the basis of the presence or absence of membranous staining and rated according to the staining status: 1 point, negative; 2 points, weak staining; 3 points, moderate staining; and 4 points, severe staining (Figure 1).

\section{Statistical Analysis}

Statistical analysis was performed using the Statistical Package for the Social Sciences for Windows 13.0 software (SPSS Inc., Chicago, IL, USA). Descriptive statistics were given as mean, standard deviation, median, min-max. Analysis of variance (ANOVA) was used for independent group comparisons. If a significant $\mathrm{p}$ value was identified between groups, we used

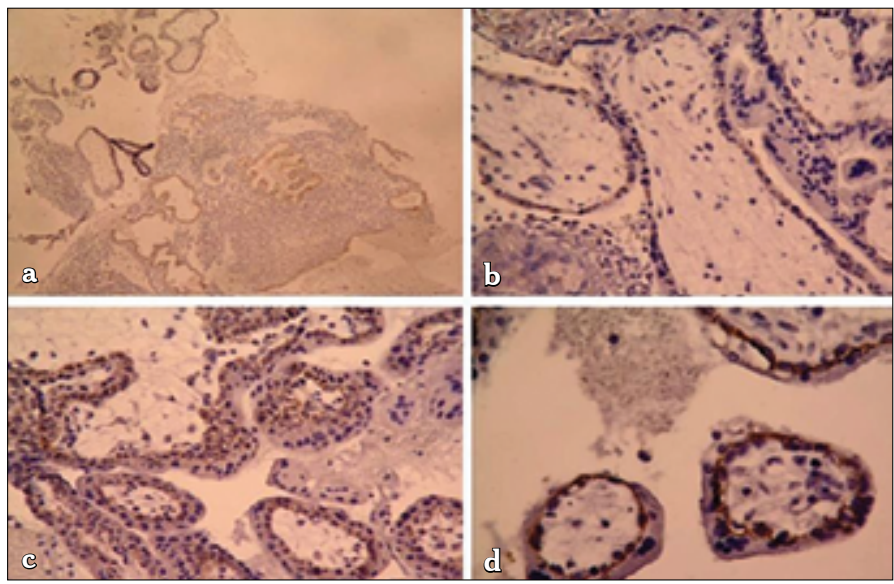

Figure 1. a-d. Immunohistochemical staining with E-selectin and P-cadherin for the villous trophoblast of first trimester human placenta. E-selectin was only positive in the endometrial glands and tubal epithelium lining (a). P-cadherin was positive for the samples of all placental villi $(b=$ weak staining, $c=$ moderate staining, $d=$ severe staining) (b-d) 
Tukey-Kramer Multiple Comparisons Test among Post hoc testing options for intergroup comparisons. We calculated a 95\% confidence interval for the results and the statistical significance was defined as $\mathrm{p}<0.05$. A two-sided $\mathrm{p}$ value was considered for all comparisons.

\section{Results}

The present study was performed on paraffin blocks of a total of 140 patients including 34 patients in the ectopic pregnancy group (Group 1), 60 patients in the spontaneous abortion group (Group 2) and 46 patients in the control group (Group 3). Patients' demographic characteristics that are shown in Table 1 showed no statistically significant difference between groups. The mean maternal age of all groups was 30.7 years and the mean gestational age was 6.8 weeks.

The average scale score for P-cadherin staining of the cells within groups is shown in Table 1. Accordingly, the average scale scores for P-cadherin staining were statistically significantly different among the three groups $(\mathrm{p}=0.0001)$, as shown in Table 2. Table 2 shows a statistically significant difference between the spontaneous abortion group and both the ectopic pregnancy $(p<0.001)$ and control groups $(p<0.001)$, but not between the ectopic pregnancy group and the control group. In addition, our study also demonstrated the presence of endometrial glandular cells and stromal P-cadherin (cadherin-3) antibodies.

Although E-selectin positivity was seen in endometrial glands and tubal epithelium lining, there was no immunoreactivity for the samples of placental villi on staining for this marker (Figure 1a). Therefore, no statistical analysis was performed for E-selectin staining.

\section{Discussion}

Implantation is a fusion between embryonic and maternal tissues which are genetically different $(1,2)$. In mammals, the embryo which has only reached the blastocyst stage can be implanted in the uterus (2). Although some of the events in implantation are similar to some of the events in tumour invasion or inflammation, implantation is different as it comprises a series of completely controlled events $(3,21)$. Especially, trophoblastic cells play very important roles in the attachment and invasion of blastocysts to the endometrium during the process of implantation $(1,2)$. Interaction between the outermost layer of the trophectoderm with a precursor of the placenta and the luminal epithelium lining of the uterus initiates implantation with a delicate equilibrium (1). Various structural, cellular and molecular changes occur in the endometrium during the preparatory period of endometrial receptivity, which is also referred to as the "window of implantation", although the uterus seems to have a limited role in the events (1). Oestrogen and progesterone hormones seem to be largely responsible for these changes $(5,6)$. Some adhesion molecules and proteins have been reported to be produced as a result of the progesteroneinduced stimulation of the endometrium prepared by oestrogen and to have an important role at various stages in reproductive physiology $(1,2,10-12)$. Following the implantation stage, the invasion of trophoblast cells in the form of a complex formation accompanied by CAMs and different proteins occurs, which eventuates in placentation. Human placenta consists of two distinct cell populations originating from cytotrophoblast stem cells, one of which is immotile villous trophoblast cells and the other is extravillous trophoblast cells that perform the invasion. Failure of the formation of uterine receptivity or abnormalities of placentation is regarded as a major aetiological factor in cases of preeclampsia, foetal growth retardation, unexplained infertility and early pregnancy loss (1, 2, 9-14, 22, 23).

Cell adhesion and migration are essential for embryonic development and tissue regeneration, but also for tumour development. CAMs are the protein molecules that are located on the cell surface and provide cell-to-cell and cell-to extracellular matrix connections $(3,9)$. They are investigated under four main groups according to their functions and structures: immuno-

Table 1. The features demographic and stain with P-cadherin of patients

\begin{tabular}{|c|c|c|c|c|}
\hline Parameters & Group 1 & Group 2 & Group 3 & $\mathbf{p}$ \\
\hline Maternal age $(y)(†)$ & $30.5 \pm 6.1$ & $30.6 \pm 5.8$ & $31.6 \pm 7.3$ & 0.800 \\
\hline Gravidity (n) (†) & $3.5 \pm 1.4$ & $3.4 \pm 1.3$ & $3.9 \pm 1.7$ & 0.510 \\
\hline Parity (n) (十) & $2.1 \pm 1.2$ & $1.6 \pm 0.9$ & $2.0 \pm 1.2$ & 0.242 \\
\hline Prior abortion (n) (†) & $0.4 \pm 0.5$ & $0.8 \pm 0.7$ & $0.8 \pm 0.7$ & 0.109 \\
\hline $\begin{array}{l}\text { Week of gestation } \\
\text { at diagnosis }(w)(+)\end{array}$ & $6.7 \pm 0.9$ & $6.7 \pm 1.3$ & $6.9 \pm 1.3$ & 0.777 \\
\hline Stain with P-cadherin $(†)$ & $2.9 \pm 0.8$ & $2.0 \pm 0.8$ & $2.8 \pm 0.8$ & $0.0001 *$ \\
\hline Total (n) & 34 & 60 & 46 & 140 \\
\hline \multicolumn{5}{|c|}{$\begin{array}{l}\text { One-way Analysis of Variance (ANOVA) test is performed. Data are pre- } \\
\text { sented as mean } \pm \text { standard deviation }\end{array}$} \\
\hline \multicolumn{5}{|c|}{ *Statistically different was defined as $\mathrm{p}<0.05$. $\mathrm{y}$; years and $\mathrm{w}$; week } \\
\hline
\end{tabular}

Table 2. Comparison among groups

\begin{tabular}{|c|c|c|c|c|}
\hline \multirow[b]{2}{*}{ Comparison } & \multirow[b]{2}{*}{ Mean Difference } & \multicolumn{2}{|c|}{ 95\% Confidence Interval } & \multirow[b]{2}{*}{$\mathbf{p}$} \\
\hline & & From & To & \\
\hline Group 2 - Group 1 & -0.8490 & -1.251 & -0.4473 & $<0.001^{*}$ \\
\hline Group 2 - Group 3 & -0.7493 & -1.116 & -0.3825 & $<0.001^{*}$ \\
\hline Group 1 - Group 3 & 0.09974 & -0.3235 & 0.5230 & $>0.05$ \\
\hline
\end{tabular}


globulin family, integrin family, selectin family and cadherins. In addition, a group of molecules that are known to have a role in the adhesion function and cannot be included in one of the groups mentioned above are termed as the unclassified adhesion molecules. CAMs play a role in the specific orientation of the cells to the tissues, cell-to-cell recognition, and regulation of events such as embryogenesis, cell growth, cell differentiation and inflammation (1, 2, 4, 9-12, 15). In some studies, adhesion molecules are emphasised to have a function in the regulation of cellular changes, gene transfer, angiogenesis, apoptosis and cellular signalling as well $(9,23)$. Damsky et al. (24) have demonstrated that cell-to-cell adhesion and signalling play a crucial role in the early implantation and relationship between the embryo and the endometrium. Abnormal levels or the absence of CAMs impedes the formation and continuation of a healthy pregnancy. For instance, a limited trophoblast invasion of maternal vessels has been correlated to both preeclampsia and foetal growth restriction, whereas an excessive trophoblast invasion is associated with invasive mole, placenta accreta and choriocarcinoma $(13,21)$. While an increase in the secretion of proteins, including adhesion molecules such as cadherin and integrin, in invading extravillous trophoblast cells prevents foetal rejection, a decrease prevents invasion and foetal growth stops (14). In our study, we assigned three groups to evaluate the efficacy of adhesion molecules in the continuation of pregnancy. We investigated whether there is any difference between the ectopic pregnancy group representing early implantation, the spontaneous abortion group that cannot provide continuation of pregnancy and the control group, with ongoing healthy pregnancy in terms of E-selectin and P-cadherin (cadherin-3) immunoreactivity.

Cadherin, a calcium-dependent transmembrane glycoprotein, is required for the expression of specific adhesion molecules in the embryo, cell migration, coalescence of cells in early embryonic tissues, and tissue differentiation (3, 9, 16-18, 25). In particular, E-cadherin plays a key role in regulating trophoblastic invasion (19). They are cell surface glycoproteins responsible for the selective cell recognition in an adult organism and lifelong normal tissue architecture $(3,25)$. Cadherins are divided into several sub groups and have more than 100 different types. The cadherin family of adhesion molecules include E-, N-, P-, $\mathrm{T}$-, and VE-cadherins, protocadherins, seven-transmembrane cadherin, and FAT-family cadherin. They are the main adhesion molecules that hold the cells together mostly in early embryonic tissues. They have been reported to play an important role in implantation in some reports $(1,15,18)$. Certain studies have demonstrated the presence of cadherin molecules in glandular epithelium and stroma of human endometrium $(3,26)$. Fujimoto et al. (10) reported that cadherins and adhesion junctions are activated for the preparation for a possible nidation following ovulation. In contrast, Damjanov et al. (27) showed that cadherins are down-regulated in the human and rat trophoblast cells during early implantation, especially during trophoblast invasion. Mac Calman et al. (11) showed the localisation of cadherin in placental syncytial trophoblasts and extravillous cytotrophoblasts that intercourse with decidualised cells in the endometrium during implantation. Among the classical cadherin group, the presence of a very low rate of P-cadherin molecule only could be demonstrated in the human placenta in previous reports (20). The expression of P-cadherin is transient in many tissues, and its permanent expression is limited to certain tissues such as the epidermis, the mesothelium, and the corneal endothelium (3). In this study, we identified P-cadherin in placental villi. P-cadherin was co-expressed with E-cadherin in local regions of various tissues, and the onset or termination of expression of P-cadherin was closely associated with the connection or segregation of cell layers, as found with other cadherins (18). The present study has also demonstrated the presence of endometrial glandular cells and stromal P-cadherin (cadherin-3) antibodies. The rate of P-cadherin staining in placental villi was found to be statistically significantly lower, particularly in abortion materials than in both ectopic pregnancy and control groups (Table 2), which suggested a potential role in the aetiology of abortion.

Selectins are cell surface carbohydrate-binding proteins that mediate the diversity of transient calcium-dependent cell-tocell adhesion interactions in blood flow (10). Selectins are a family of CAMs which bind to specific sugar determinants on the surface of adjacent cells which act as adhesion counterreceptors. The selectin family includes leukocyte-expressed L-selectin (CD62L), endothelial-expressed E-selectin (CD62E), and P-selectin (CD62P), which is expressed by both platelets and endothelial cells. Many researchers argued that pregnancy and labour are an inflammatory reaction in which cell adhesion molecules play an important role. In this regard, the E-selectin molecule is presented from cytokine-induced endothelial cells and mediates the activation of neutrophils, monocytes, and lymphocytes $(10,12,28)$. They provide a loose association between leukocytes and endometrial endothelial cells and help leukocytes to roll on the endothelium. Following this activation, the integrin group of adhesion molecules is released and provides more potent intercellular binding. In our study, all paraffin blocks analysed for E-selectin immunoreactivity showed varying degrees of staining in endometrial glands in the field of view and tubal epithelium lining. However, the foetal placental villi showed no E-selectin immunoreactivity (Figure 1a). This result suggests that E-selectin adhesion molecules arise as a result of temporary and inflammatory reactions, thus playing a role in implantation, but does not take a role in placentation.

In conclusion, the lack of E-selectin immunoreactivity in foetal villi suggests that this molecule emerges as a result of temporary and inflammatory reaction in the early stage of implantation. Our results also suggest that the statistically significantly lower P-cadherin immunoreactivity in foetal placental villi found in the spontaneous abortion group compared to the ectopic pregnancy and control groups, plays an important role in the aetiopathogenesis of spontaneous abortion and that higher P-cadherin levels are needed for the continuation of pregnancy. Larger and more recent studies are needed for the association of adhesion molecules with the aetiopathogenesis of ectopic pregnancy.

Ethics Committee Approval: Ethics committee approval was received for this study.

Informed Consent: Written informed consent was obtained from patients who participated in this study. 
Peer-review: Externally peer-reviewed.

Author contributions: Concept - H.S.,; Design - H.Ş., A.R.E.; Supervision - A.R.E., D.D.; Resource - H.S., Y.K.A., I.G.; Materials H.Ş., U.B.; Data Collection\&/or Processing - H.S., U.B.; Analysis\&/ or Interpretation - H.S.,; Literature Search - H.S.., Y.K.A., I.G.; Writing - H.S., Y.K.A., I.G.; Critical Reviews - Y.K.A., I.G., D.D.

Conflict of Interest: No conflict of interest was declared by the authors.

Financial Disclosure: The authors declared that this study received financial support from Gülhane Military Medical Academy.

\section{References}

1. Kimber SJ. Molecular interactions at the maternal-embryonic interface during the early phase of implantation. Semin Reprod Med 2000; 18: 237-53. [CrossRef]

2. Kimber SJ. Molecular interactions at the maternal-embryonic interface during the early phase of implantation. Semin Reprod Med 2000; 18: 237-23. [CrossRef]

3. Campbell S, Swann HR, Seif MW, Kimber SJ, Aplin JD. Cell adhesion molecules on the oocyte and preimplantation human embryo. Hum Reprod 1995; 10: 1571-8. [CrossRef]

4. Duc-Goiran P, Mignot TM, Bourgeois C, Ferré F. Embryo-maternal interactions at the implantation site: a delicate equilibrium. Eur $\mathrm{J}$ Obstet Gynecol Reprod Biol 1999; 83: 85-100. [CrossRef]

5. Reddy KV, Mangale SS. Integrin receptors: the dynamic modulators of endometrial function. Tissue Cell 2005; 35: 260-73. [CrossRef]

6. Genbacev OD, Prakobphol A, Foulk RA, Krtolica AR, Ilic D, Singer MS, et al. Trophoblast L-selectin-mediated adhesion at the maternal-fetal interface. Science 2003; 299: 405-8. [CrossRef]

7. Lessey BA. Integrins and the endometrium: new markers of uterine receptivity. Ann N Y Acad Sci 1997; 828: 111-22. [CrossRef]

8. Achache H, Revel A. Endometrial receptivity markers, the journey to successful embryo implantation. Hum Reprod Update 2006; 12: 731-46. [CrossRef]

9. Aplin JD, Jones CJ, Harris LK. Adhesion molecules in human trophoblast - a review. I. Villous trophoblast. Placenta 2009; 30: 293-8. [CrossRef]

10. Fujimoto J, Ichigo S, Hori M, Tamaya T. Alteration of E-cadherin, alpha- and beta-catenin mRNA expression in human uterine endometrium during the menstrual cycle. Gynecol Endocrinol 1996; 10: 187-91. [CrossRef]

11. MacCalman CD, Furth EE, Omigbodun A, Bronner M, Coutifaris C, Strauss JF 3rd. Regulated expression of cadherin-11 in human epithelial cells: a role for cadherin-11 in trophoblast-endometrium interactions? Dev Dyn 1996; 206: 201-11. [CrossRef]

12. Nose A, Takeichi M. A novel cadherin cell adhesion molecule: its expression patterns associated with implantation and organogenesis of mouse embryos. J Cell Biol 1986; 103: 2649-58. [CrossRef]
13. Brown LM, Lacey HA, Baker PN, Crocker IP. E-cadherin in the assessment of aberrant placental cytotrophoblast turnover in pregnancies complicated by pre-eclampsia. Histochem Cell Biol 2005; 124: 499-506. [CrossRef]

14. Lyall F, Bulmer JN, Duffie E, Cousins F, Theriault A, Robson SC. Human trophoblast invasion and spiral artery transformation: the role of PECAM-1 in normal pregnancy, preeclampsia, and fetal growth restriction. Am J Pathol 2001; 158: 1713-21. [CrossRef]

15. Jauniaux E, Burton GJ. Pathophysiology of histological changes in early pregnancy loss. Placenta 2005; 26: 114-23. [CrossRef]

16. Paria BC, Lim H, Wang XN, Liehr J, Das SK, Dey SK. Coordination of differential effects of primary estrogen and catecholestrogen on two distinct targets mediates embryo implantation in the mouse. Endocrinology 1998; 139: 5235-46. [CrossRef]

17. Lessey BA, Yeh I, Castelbaum AJ, Fritz MA, Ilesanmi AO, Korzeniowski $\mathrm{P}$, et al. Endometrial progesterone receptors and markers of uterine receptivity in the window of implantation. Fertil Steril 1996; 65: 477-83.

18. Sunder S, Lenton EA. Endocrinology of the peri-implantation period. Baillieres Best Pract Res Clin Obstet Gynaecol 2000; 14: 789-800. [CrossRef]

19. Batistatou A, Makrydimas G, Zagorianakou N, Zagorianakou P, Nakanishi Y, Agnantis NJ, et al. Expression of dysadherin and E-cadherin in trophoblastic tissue in normal and abnormal pregnancies. Placenta 2007; 28: 590-2. [CrossRef]

20. Shimoyama Y, Yoshida T, Terada M, Shimosato Y, Abe O, Hirohashi S. Molecular cloning of a human $\mathrm{Ca} 2+$-dependent cell-cell adhesion molecule homologous to mouse placental cadherin: its low expression in human placental tissues. J Cell Biol 1989; 109: 1787-94. [CrossRef]

21. Charalabopoulos K, Binolis J, Karkabounas S. Adhesion molecules in carcinogenesis. Exp Oncol 2002; 24: 249-57.

22. Lunghi L, Ferretti ME, Medici S, Biondi C, Vesce F. Control of human trophoblast function. Reprod Biol Endocrinol 2007; 5: 6. [CrossRef]

23. Bischoff J. Cell adhesion and angiogenesis. J Clin Invest 1997; 99: 373-6. [CrossRef]

24. Damsky C, Sutherland A, Fisher S. Extracellular matrix 5: adhesive interactions in early mammalian embryogenesis, implantation, and placentation. FASEB J 1993; 7: 1320-9.

25. Paredes J, Figueiredo J, Albergaria A, Oliveira P, Carvalho J, Ribeiro AS, et al. Epithelial E- and P-cadherins: Role and clinical significance in cancer. Biochim Biophys Acta 2012; 1826: 297-311.

26. van der Linden PJ, de Goeij AF, Dunselman GA, Arends JW, Evers JL. P-cadherin expression in human endometrium and endometriosis. Gynecol Obstet Invest 1994; 38: 183-5. [CrossRef]

27. Damjanov I, Damjanov A, Damsky CH. Developmentally regulated expression of the cell-cell adhesion glycoprotein cell-CAM 120/80 in peri-implantation mouse embryos and extraembryonic membranes. Dev Biol 1986; 116: 194-202. [CrossRef]

28. Bevilacqua MP. Endothelial-leukocyte adhesion molecules. Annu Rev Immunol 1993; 11: 767-804. [CrossRef] 